\title{
Simple Electrochemical Determination of Hydrazine in Water
}

\author{
Lukas Lauko', Roman Hudec ${ }^{1}$, Katarina Lenghartova ${ }^{2}$, Alena Manova ${ }^{1}$, \\ Frantisek Cacho ${ }^{1}$, Ernest Beinrohr ${ }^{1,2 *}$ \\ 'Institute of Analytical Chemistry, Faculty of Chemical and Food Technology, \\ Slovak University of Technology in Bratislava, Radlinskeho 9, 81237 Bratislava, Slovakia \\ ${ }^{2}$ Department of Chemistry, Faculty of Natural Sciences, University of SS. Cyril and Methodius in Trnava, \\ J. Herdu 2, 91701 Trnava, Slovakia
}

Received: 2 March 2015

Accepted: 25 March 2015

\begin{abstract}
Hydrazine in water samples is determined by constant current chronopotentiometry in porous carbon electrodes. Hydrazine in alkaline solutions is oxidised to nitrogen in the pores of the electrode by constant current. Two types of electrodes made of reticulated vitreous carbon (RVC) were used, one fabricated from crushed RVC particles, the other with the original RVC material of 100 ppi porosity. The former is suitable for hydrazine concentrations above $0.7 \mathrm{mg} \cdot \mathrm{dm}^{-3}$ up to $50 \mathrm{mg} \cdot \mathrm{dm}^{-3}$, the latter for the $8-700 \mu \mathrm{g} \cdot \mathrm{dm}^{-3}$ range. The method was used for water samples, including boiler water.
\end{abstract}

Keywords: hydrazine determination, boiler water, constant current chronopotentiometry, porous electrode, vitreous carbon

\section{Introduction}

Hydrazine is a powerful reducing agent widely used in industry and agriculture. It is employed as a corrosion inhibitor in boilers, a reactant in military fuel cells, rocket propellant, antioxidant, catalyst, and pesticide. Hydrazine in boiler water is an effective chemical oxygen scavenger reacting with oxygen to yield nitrogen and water only. The reaction products add no solids, salts, and organics to the boiler water and are not corrosive to ferrous metals. For these reasons, hydrazine is preferred over sodium sulphite as an oxygen scavenger in high-pressure boiler water applications. Theoretically, $1 \mathrm{mg}$ of hydrazine can react with $1 \mathrm{mg}$ of oxygen. Unreacted hydrazine can be decomposed to form ammonia, which may corrode copper or copper-containing alloys. To avoid excess formation of ammonia, the hydrazine concentration is kept at a relatively low

*e-mail: ernest.beinrohr@stuba.sk level, preferably around $0.1 \mathrm{mg} / \mathrm{dm}^{3}$ or less. Control of the hydrazine concentration is therefore requested.

However, hydrazine is toxic and may be easily absorbed by oral, dermal, or inhalation routes of exposure. The lungs, liver, kidney, and central nervous systems of living organisms can be injured if hydrazine is inhaled or introduced to the skin. Hence the detection and determination of hydrazine in technological materials and environments is of growing importance.

Several techniques such as spectrophotometry $[1,2]$, coulometry [3], amperometry [4], potentiometry [5], titrimetry [6], and chemiluminescence [7] have been reported for determining hydrazine. The direct electrochemical oxidation of hydrazine has been studied on several electrodes, including mercury [8, 9], nickel [10], silver, gold [811], and platinum [12].

The mechanism of the electrochemical oxidation of hydrazine was investigated at various electrode surfaces in various electrolyte solutions and $\mathrm{pH}$ values [13-16]. 
The oxidation product was detected to be dinitrogen, hence the electrode reaction involves four electrons:

$$
\mathrm{N}_{2} \mathrm{H}_{4} \rightarrow \mathrm{N}_{2}+4 \mathrm{H}^{+}+4 \mathrm{e}^{-}
$$

However, the $\mathrm{Ag}, \mathrm{Au}$, and $\mathrm{Pt}$ electrodes require large overpotentials for hydrazine oxidation [17]. Graphite electrodes with gold [18], copper-palladium [19] nanoparticles, and chemically modified electrodes [17-20] have also been tested for hydrazine detection in water samples. Hydrazine was measured with a rotating platinum electrode [21] and carbon paste electrodes [22, 23]. Owing to the oxidation overpotential on most electrode surfaces, homogenous [2325] or heterogeneous catalysts have been frequently usedthe latter in the form of modified electrode surfaces such as copper oxide nanoparticles on glassy carbon [26], Pt nanoparticles in carbon nanotubes [27], Ru-modified glassy carbon [28], carbon paste electrode modified with p-phtalocyanine [29], and glassy carbon modified with gold-copper nanoparticles in graphene [30]. Palladium nanoarray electrode in a carbon-epoxy composite material exhibited catalytic effects toward hydrazine oxidation [31]. These methods allow the determination of hydrazine down to a few $\mu \mathrm{g} / \mathrm{L}$, but are less suitable for routine use owing to the laborious preparation of electrode materials.

Porous electrodes made of reticulated vitreous carbon (RVC) and glassy carbon particles exhibit some special features that make them attractive for electrochemical measurements. Their large surface and small void volume facilitate direct coulometric titrations [32]. The goal of this paper is to demonstrate the utility of such electrode materials for a simple and fast determination of hydrazine in water samples.

\section{Materials and Methods}

\section{Instruments}

The flow-through chronopotentiometric measurements were carried out on an EcaFlow GLP 150 flow-through electrochemical analyser (Istran, Ltd., Bratislava, Slovakia) equipped with two solenoid inert valves, a peristaltic pump, and a microprocessor-controlled potentiostat/galvanostat. The block diagram and the operation mode of the system were given earlier [33]. The signals were recorded and evaluated by the memory-mapping technique [34, 35], which makes use of a fast measurement of the potential of the working electrode (the measuring frequency was more than 70,000 per second in the applied system), whereas the measured values are collected in a channel counter, with each channel corresponding to a potential. On finishing the measurement the content of the channel counter is displayed and evaluated. Hence, not the potential versus time dependence is recorded and displayed but the number of counts (how many times a potential value was measured) against this potential. The total number of counts within a peak multiplied by the reciprocal of the measuring frequency gives the corresponding transition time, $\tau$.
Table 1. Operational parameters of the electrochemical analyzer.

\begin{tabular}{|l|c|c|}
\hline \multicolumn{1}{|c|}{ Parameter } & Dimension & Value \\
\hline Filling potential & $\mathrm{mV}$ & 200 \\
\hline Quiescence potential & $\mathrm{mV}$ & 200 \\
\hline Quiescence time & $\mathrm{s}$ & 5 \\
\hline Terminal potential & $\mathrm{mV}$ & 900 \\
\hline Standby potential & $\mathrm{mV}$ & 800 \\
\hline Oxidation current & $\mu \mathrm{A}$ & $\begin{array}{c}200 \text { (Electrode E-53) } \\
5 \text { (Electrode E-104) }\end{array}$ \\
\hline Flow rate & $\mathrm{mL} \cdot \mathrm{min}^{-1}$ & 6 \\
\hline
\end{tabular}

The measurement consisted of two main steps:

i) the background signal was measured first by means of the blank sample,

ii) then the sample or standard solution was measured.

The background signal was then subtracted from this signal, yielding a true background corrected net signal. Both steps consisted of several sequences:

i) the cell was filled with the sample or standard solution at the filling potential where no electrode reaction had occurred,

ii) the flow was stopped,

iii) a constant current was applied to oxidise hydrazine in the electrode pores,

iv) the potential was monitored until it reached terminal value.

The cell was then rinsed with the electrolyte solution. The operation parameters are listed in Table 1.

Compact flow-through electrochemical cells of type $353 \mathrm{c}$ and 104 with Pt auxiliary and built-in $\mathrm{Ag} / \mathrm{AgCl}$ reference electrodes were employed. As working electrodes the microporous E-53 and macroporous E-104 electrodes were used (all from Istran, Ltd., Bratislava, Slovakia). Electrode E-53 was made of a carbon cylinder (height $4 \mathrm{~mm}$, inner and outer diameters $5 \mathrm{~mm}$ and $10 \mathrm{~mm}$, respectively). The cylinder was filled with crushed reticulated vitreous carbon material and closed from both sides with porous frits. The effective volume and active surface area of the electrode were approximately $20 \mu \mathrm{L}$ and $25 \mathrm{~cm}^{2}$, respectively. The pores in the electrode were irregular with diameters of 5 to $20 \mu \mathrm{m}$. Electrode E-104 was fabricated from a reticulated vitreous carbon plug of 100 ppi (pores per inch) porosity (Electrosynthesis Co. Inc., Lancaster, New York, USA) with $10 \mathrm{~mm}$ and $4 \mathrm{~mm}$ in diameter and length, respectively. Its effective volume and active surface area of the electrode were $300 \mu \mathrm{L}$ and $17 \mathrm{~cm}^{2}$, respectively. The pores were almost regular with diameters of about $500 \mu \mathrm{m}$.

The potentials throughout this paper are expressed against the $\mathrm{Ag} / \mathrm{AgCl}$ reference electrode.

The accuracy of the results was checked by spectrophotometry on a Spectronic 20 Genesys (Thermo Electron Corporation) spectrophotometer by making use of the colour reaction of hydrazine with p-dimethylaminobenzaldehyde in acidic media [1]. 


\section{Reagents and Solutions}

Analytical-grade reagents were used in all experiments. Deionised and degassed water was used for the preparation of all solutions. The carrier electrolyte was $0.1 \mathrm{~mol} \cdot \mathrm{dm}^{-3}$ $\mathrm{Na}_{2} \mathrm{HPO}_{4}$.

Electrolytes for sample adjustment were: Electrolyte A was $1.0 \mathrm{~mol} \cdot \mathrm{dm}^{-3} \mathrm{Na}_{2} \mathrm{HPO}_{4}$ and electrolyte $\mathrm{B}$ was a borate buffer $\left(0.5 \mathrm{~mol} \cdot \mathrm{dm}^{-3} \mathrm{NaCl}, 0.5 \mathrm{~mol} \cdot \mathrm{dm}^{-3} \mathrm{H}_{3} \mathrm{BO}_{3}\right.$, and 0.25 $\left.\mathrm{mol} \cdot \mathrm{dm}^{-3} \mathrm{NaOH}\right)$.

The bulk solution of hydrazine $\left(0.1 \mathrm{~mol} \cdot \mathrm{dm}^{-3}\right)$ was prepared by dissolving $\mathrm{N}_{2} \mathrm{H}_{4} \cdot \mathrm{H}_{2} \mathrm{SO}_{4}$ in water. Calibration and test solutions of hydrazine were prepared always fresh in $0.1 \mathrm{~mol} \cdot \mathrm{dm}^{-3} \mathrm{Na}_{2} \mathrm{HPO}_{4}$.

\section{Sampling and Sample Preparation}

The tap and river water samples were analysed immediately after sampling. The boiler water sample stabilised with hydrochloric acid was neutralised with $\mathrm{NaOH}$ solution and analyzed.

\section{Procedure}

To a $100 \mathrm{~mL}$ dry volumetric flask $10 \mathrm{~mL}$ of $1.0 \mathrm{~mol} \mathrm{dm}$ $3 \mathrm{Na}_{2} \mathrm{HPO}_{4}$ or $20 \mathrm{ml}$ of the borate buffer solution was added and the volume was adjusted to $100 \mathrm{~mL}$ with the sample. The $\mathrm{pH}$ of the phosphate and borate solutions were 9.0 and 9.1 , respectively.

The blank samples were prepared in the same way just pure water was used instead of the sample. The calibration curve technique was used for evaluation of the results.

\section{Results and Discussion}

Constant current chronopotentiometry in porous electrodes is in fact an in-electrode coulometric titration based on direct electrolysis of analyte in the bulk of a porous electrode. It is in fact a coulometric measurement in a thin layer of solution [36], but with a much more robust design than planar thin-layer arrangements. Unlike classical coulomet- ric titrations, a chemical titrant need not be produced because the analyte is titrated directly by electrical charge. Moreover, owing to the low current densities used here, the potential of the porous electrode is controlled by the oxidation-reduction couple being engaged in the titration. This allows one to assess the titration endpoint in a simple way. Hence, no additional indication system is demanded, the working electrode serves as a "generating" as well as "indicator" electrode. Since the electrolysis is performed virtually in the diffusion layer only, no mixing of the solution is needed, making the system extremely simple. The completeness of the electrolysis in the electrode bulk depends on pore size, current density, and diffusion constants. Small pores and low current densities ensure higher electrochemical recoveries and vice versa. Small pores, however, mean higher electrode surface and higher background currents deteriorating the measurement of low analyte concentrations. Low current densities, on the other hand, enhance the measurement time. Hence both parameters should be optimised. Since there was no way to influence the porosity in the used commercial electrodes, only the oxidation current was optimized.

Theoretically, knowing the void volume of the porous electrode and anticipating a complete electrochemical recovery, the analyte amount could be directly obtained by means of Faraday's laws of electrolysis from the electrical charge consumed, hence the method is in principle calibrationless [37]. The void volume of the electrode can be extracted from the porosity data of the electrode or, even better, by coulometric measurement of solutions with known analyte contents under conditions that ensure complete electrochemical yields. However, if the measurement is performed in calibration mode, complete electrochemical yields are no longer a prerequisite.

The electrochemical oxidation of hydrazine in porous glassy carbon electrodes proceeds in slightly acidic, neutral, and alkaline solutions at potentials depending on the $\mathrm{pH}$ value.

The cyclic voltamograms revealed a completely irreversible oxidation of hydrazine (Fig. 1). The oxidation peak potential depended on the $\mathrm{pH}$ value and was shifted to more negative values when increasing the $\mathrm{pH}$. There was no oxidation peak in the second and consecutive runs - only a

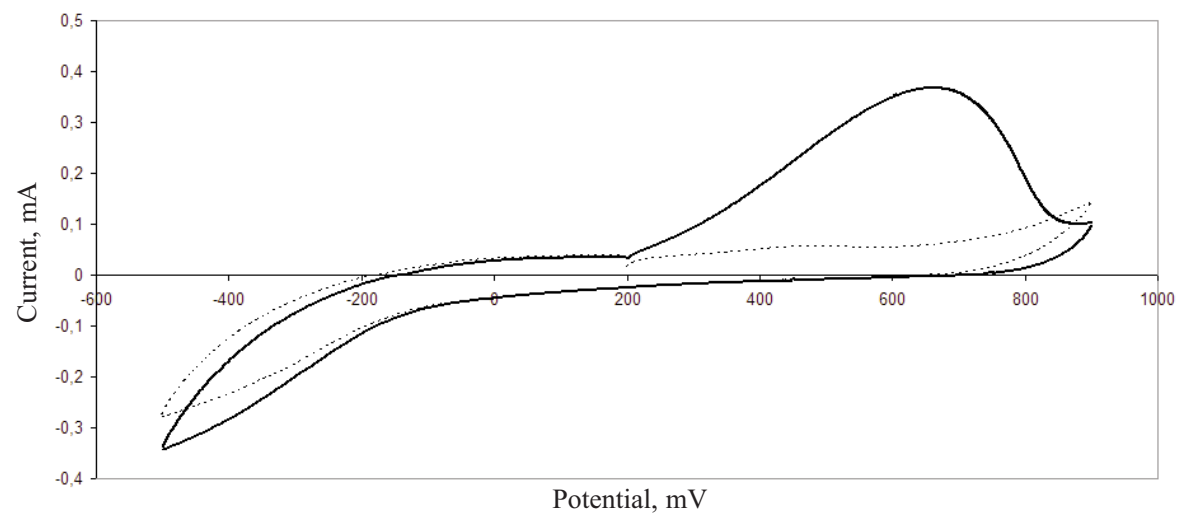

Fig. 1. Cyclic voltamograms of $0.001 \mathrm{~mol} \cdot \mathrm{dm}^{-3}$ hydrazine in $0.1 \mathrm{~mol} \cdot \mathrm{dm}^{-3} \mathrm{Na}_{2} \mathrm{HPO}_{4}$. Scan rate $10 \mathrm{mV} \cdot \mathrm{s}^{-1}$, starting potential $200 \mathrm{mV}$. Full line - first run, dotted line - second run. Electrode E-53. 
slight decrease of the cathodic wave. Hence the oxidation of hydrazine is completely irreversible, as well as the reduction of dissolved oxygen that caused the decrease of the cathodic current in the consecutive runs. Assuming a complete electrochemical conversion, the coulombic content of the oxidation peak implied a charge number of 4 of the electrode reaction, which was confirmed by chronopotentiometric measurements (vide infra). The oxidation peak was broad and asymmetric, presumably due to the irreversibility of the electrode reaction.

\section{Stoichiometry}

Complete electrochemical yields can be achieved in the microporous electrode [37], and the charge number $\mathrm{z}$ of the electrode reaction can be obtained by making use of Faraday's laws of electrolysis:

$$
z=I \tau /(F c V)
$$

... where $I$ denotes the applied current, $\tau$ is chronopotentiometric transition time, $F$ is Faraday constant, $c$ is analyte concentration, and $V$ is the effective void volume of the electrode. The last parameter was determined by analysing ferrocyanide solutions of known concentrations in $\mathrm{KCl}$ electrolyte under the same conditions as the hydrazine measurement (Table 1). The effective void volume of the employed E-53 electrode was found to be (17.5 \pm 0.9$) \mu \mathrm{L}$. By making use of this value, the charge number $\mathrm{z}$ of the electrode reaction of hydrazine was found to be $3.9 \pm 0.2-$ close to the expected value of 4 .

As in cyclic voltammetry, the position of the oxidation peak of hydrazine was influenced by $\mathrm{pH}$ value (Fig. 2): the more acidic the solution, the more positive the oxidation potential and vice versa, in accordance with the electrode reaction (1) and the corresponding Nernst equation. In acidic solutions the oxidation peak is shifted to potentials where the electrode surface may be corroded and the signal coalesces with the background, resulting in low reproducibility. The dissociation constant of hydrazine is $p \mathrm{~K}_{\mathrm{a}}=8.10$ [38] and therefore below $\mathrm{pH} 7$ the significant protonation of the hydrazine molecules hampers the oxidation.

\section{Optimization of Experimental Parameters}

Alkaline solutions ensured a better resolution of the oxidation peak and higher reproducibility. However, at high $\mathrm{pH}$ values the oxidation of hydroxide anions to oxygen enhanced the background level significantly or even obscured the hydrazine signal. Solutions with $\mathrm{pH}$ values of 8 to 12 provided well-resolved oxidation peaks with low background levels. As an electrolyte, $0.1 \mathrm{~mol} \cdot \mathrm{dm}^{-3}$ $\mathrm{Na}_{2} \mathrm{HPO}_{4}$ solution with $\mathrm{pH} 9$ was used in further experiments. For real samples the borate buffer solution with pH 9.1 was preferred owing to its higher buffering capacity.

The oxidation peak obtained by making use of a new E-104 electrode was lower than usual and was shifted to positive potentials and partially obscured by the background signal. During consecutive measurements the peak was enhanced, moved to more negative values, and eventually stabilised. This was reached after 10-20 measurements. To avoid this initialising period, the new electrode was filled with the carrier electrolyte and activated 5-10 min at a potential of $1200 \mathrm{mV}$. Although the background level enhanced, the oxidation peak became well separated from the oxidation signal of the electrolyte (Fig. 3) and remained stable over several weeks of operation. The signal of the E-53 electrode was stable from the very beginning and no activation was used for it.

The results were influenced by the standby potential. Off-circuiting the cell between measurements caused the first result to be lower than the consecutive ones. Applying a standby potential of 700-900 $\mathrm{mV}$ eliminated the deactivation of the electrode surface. More positive potentials did not improve the performance and instead simply enhanced significantly the background level; lower values did not hinder electrode deactivation.

The sensitivity of the chronopotentiometric measurement in thin layers or small pores is inversely proportional to the current (Eq. 2). Hence the signal can be enhanced by decreasing the current. However, a fraction of the current is always consumed for non-faradaic processes such as double layer charging, electrode surface processes that limit the value of the lowest usable current. Additionally, too low currents may considerably prolong the measurement.

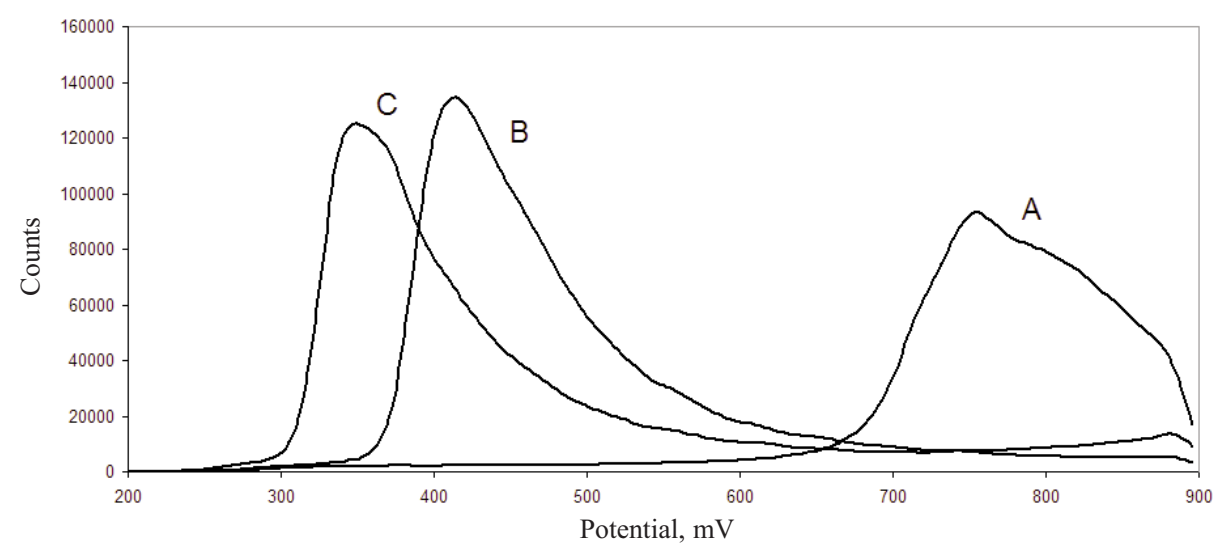

Fig. 2. Chronopotentiograms of $30 \mathrm{mg} \cdot \mathrm{dm}^{-3}$ hydrazine in $0.1 \mathrm{~mol} \cdot \mathrm{dm}^{-3} \mathrm{Na}_{2} \mathrm{HPO}_{4}$ adjusted to $\mathrm{pH} 5.5$ (A), 8.0 (B), and 10.0 (C). Electrode E-53, oxidation current $200 \mu \mathrm{A}$. 


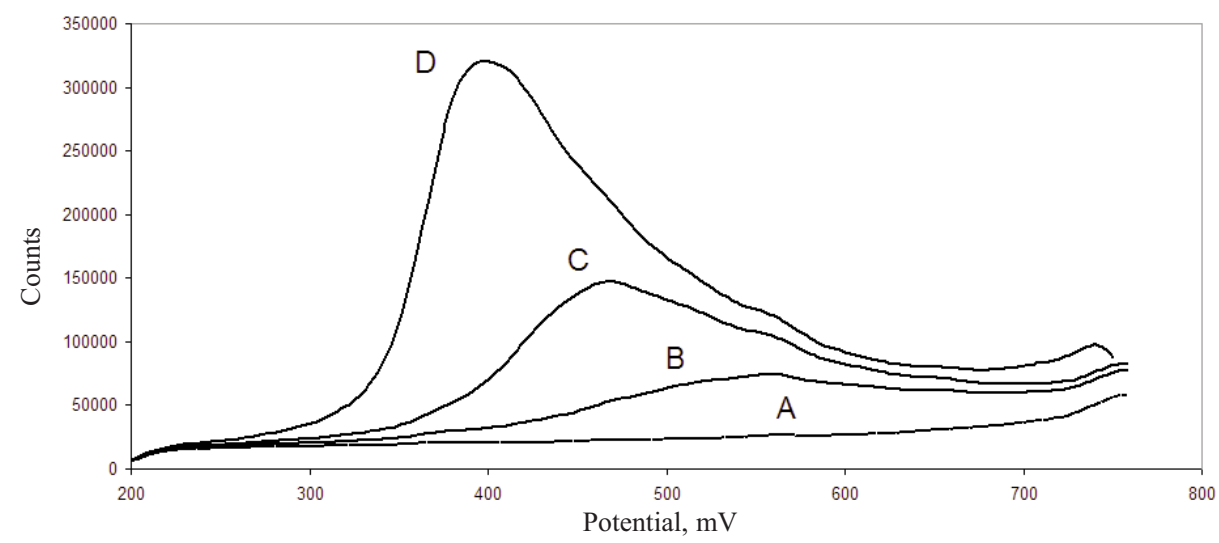

Fig. 3. Chronopotentiograms of hydrazine in borate buffer (pH 9). A - blank, B $-50 \mu \mathrm{g} \cdot \mathrm{dm}^{-3}, \mathrm{C}-100 \mu \mathrm{g} \cdot \mathrm{dm}^{-3}, \mathrm{D}-250 \mu \mathrm{g} \cdot \mathrm{dm}^{-3}$, electrode E-104, oxidation current $5 \mu \mathrm{A}$.

High currents, on the other hand, produce signals of lower reproducibility and linearity, the latter being critical in the case of macroporous electrodes. For electrode E-53 currents of $100-200 \mu \mathrm{A}$ corresponding to current densities of 4-8 $\mu \mathrm{A} \cdot \mathrm{cm}^{-2}$ were used, which ensures linearity in a broad concentration range and fast measurement. Owing to the large pore diameters in the E-104 electrode, much lower current densities had to be used to ensure a linear response. The optimum value ensuring both linearity and reasonable measurement times was found to be $5 \mu \mathrm{A}$ (current density $0.3 \mu \mathrm{A} \cdot \mathrm{cm}^{-2}$ ). Currents above $10 \mu \mathrm{A}$ gave rise to considerable non-linearity and the $\tau$ vs $c$ relation became closer to the non-linear Sand equation [39]. Lower currents produced linear responses but considerably prolonged the measurements.

\section{Figures of Merit}

The concentration range was tested up to $100 \mathrm{mg} \cdot \mathrm{dm}^{-3}$ of hydrazine. The response was found to be linear up to 0.7 and $50 \mathrm{mg} \cdot \mathrm{dm}^{-3}$ for the E-104 and E-53 electrodes, respectively (Figs. 4 and 5). Concentrations above $50 \mathrm{mg} \cdot \mathrm{dm}^{-3}$ were not tested because such high concentrations are not common in the tested sample types.

The lower concentration range was used for estimation of limits of detection and quantification according to a procedure recommended by IUPAC [40] (Table 2). The repeatability of the measurement was calculated from 10 measurements of hydrazine solutions in a short sequence. For reproducibility assessment, solutions with the same concentration were analysed in an interval of 10 days.

There is a significant difference in the concentration ranges between the two types of electrodes. The macroporous electrode E-104 enables the determination of much lower concentrations than the E-53 one. On the other hand, the latter one can measure significantly higher concentrations than the former. This difference originates in the different electrode volume-to-surface ratios (V/A), which determine the corresponding signal-to-background ratios (S/B). A higher V/A ratio ensures a higher S/B ratio, which is a prerequisite for a lower detection limit. Hence, the E-53 electrode with $\mathrm{V} / \mathrm{A}$ ratio of about $0.0008 \mathrm{~cm}$ is suitable only for hydrazine concentrations above $0.7 \mathrm{mg} \cdot \mathrm{dm}^{-3}$. The E-104 electrode with a much higher V/A ratio of approximately $0.018 \mathrm{~cm}$ facilitates the measurement of concentrations of less than $700 \mu \mathrm{g} \cdot \mathrm{dm}^{-3}$ down to $8 \mu \mathrm{g} \cdot \mathrm{dm}^{-3}$.

Reproducibility and repeatability are similar for both electrodes. An advantage of the E-104 electrode, in addition to its higher sensitivity, is that colloidal particles are tolerated in the sample. The E-53 electrode requires clean or filtered solutions, otherwise the pores of the frits and the electrode material may be blocked.

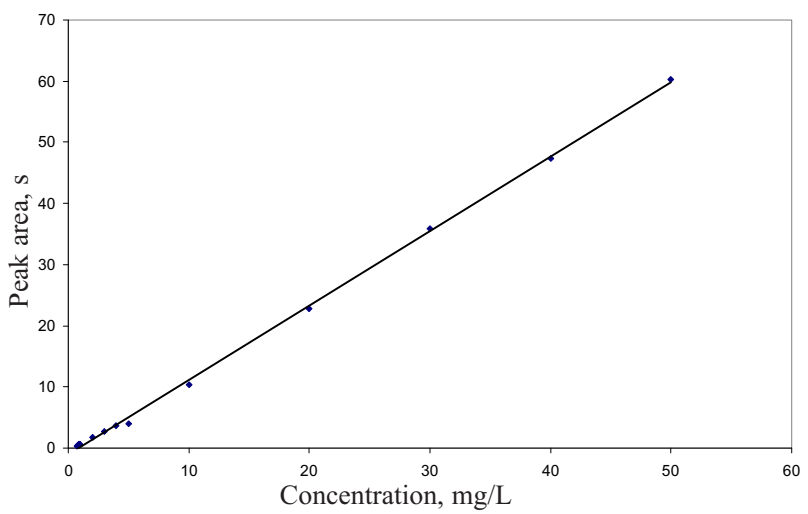

Fig. 4. Concentration dependence of the hydrazine signal. Electrode: E53; regression line: $\mathrm{y}=1.2152 \mathrm{x}-0.9528$; coefficient of determination $\mathrm{R}^{2}=0.9993$.

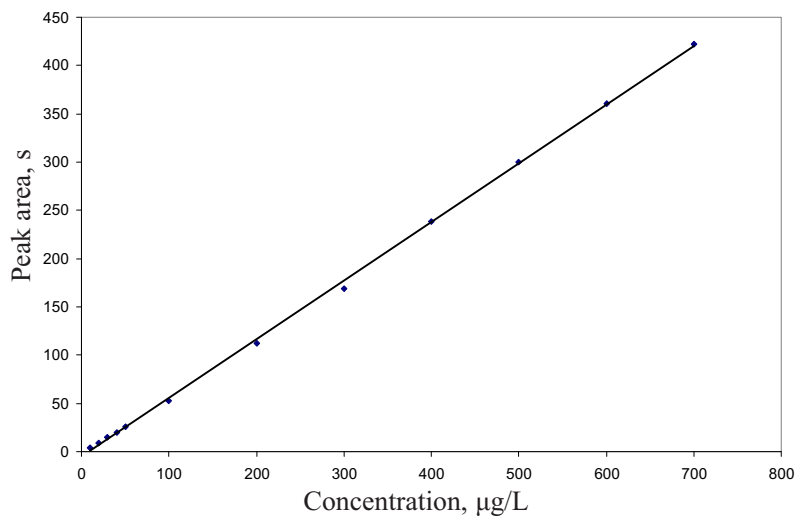

Fig. 5. Concentration dependence of the hydrazine signal. Electrode: E104; regression line: $y=0.6075 x-5.4129$; coefficient of determination $\mathrm{R}^{2}=0.9995$. 
Table 2. Analytical figures of merit.

\begin{tabular}{|l|c|c|c|}
\hline \multirow{2}{*}{\multicolumn{1}{|c|}{ Parameter }} & \multirow{2}{*}{ Dimension } & \multicolumn{2}{c|}{ Value } \\
\cline { 3 - 4 } & & E-53 & E-104 \\
\hline Limit of detection & $\mu \mathrm{g} \cdot \mathrm{dm}^{-3}$ & 180 & 7,8 \\
\hline Limit of quantification & $\mu \mathrm{g} \cdot \mathrm{dm}^{-3}$ & 650 & 23 \\
\hline Linear range & $\mathrm{mg} \cdot \mathrm{dm}^{-3}$ & $0.2-50$ & $0.008-0.7$ \\
\hline Repeatability & $\%$ & 1.5 & 1.4 \\
\hline Reproducibility & $\%$ & 3.0 & 2.8 \\
\hline Duration of a measurement & $\mathrm{min}$ & 3 & 5 \\
\hline
\end{tabular}

\section{Interferences}

There are only a few substances that could potentially interfere at the electrochemical oxidation of hydrazine, including iodides, ascorbic acid, and sulphite, but these are not common in real water samples. Interferences originate more likely in precipitation of some ions such as Fe(II), $\mathrm{Fe}(\mathrm{III})$, and $\mathrm{Cu}(\mathrm{II})$ in the alkaline sample solution. The precipitate may clog the pores of the electrode and/or block the electrode surface, causing a signal drop. The addition of EDTA to the sample prior to the electrolyte prevents precipitation. Excess of other ions common in water samples (Ca(II), $\mathrm{Mg}(\mathrm{II})$, chloride, sulphate, carbonate, and nitrate) did not affect the signal. Ammonia at concentrations above $2 \mathrm{mg} \cdot \mathrm{dm}^{-3}$ caused a slight decrease of the signal (Fig. 6), which can be assigned to the slow oxidation of ammonia yielding an enhanced background level that distorts the oxidation peak of hydrazine.

\section{Real Samples}

Several water samples were analyzed by the elaborated method, including surface water, drinking water, and boiler

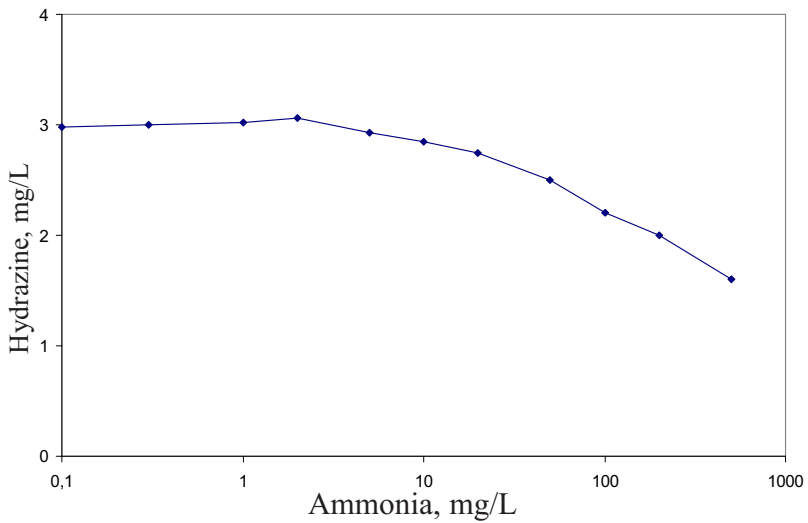

Fig. 6. Influence of ammonia content on the signal of hydrazine. Electrode E-53 (parameters listed in Table 1).

water coming from a power plant. The hydrazine content in these samples was below $1 \mathrm{mg} \cdot \mathrm{dm}^{-3}$ and therefore the E-104 electrode was used. Sample adjustment was done with the borate buffer. The reference values were obtained by the spectrophotometric method. There was an acceptable match between the chronopotentiometric and photometric measurements, the former being slightly less reproducible (Table 3). For the boiler water samples the results were lower than the informative values, which was probably caused by partial decomposition of hydrazine - especially in the non-stabilized samples (these samples were analyzed a week after sampling). The value for the stabilised sample was closer to the informative one. Spikes to these samples resulted in appropriate signal enhancement with recoveries of $95-103 \%$.

\section{Conclusions}

Hydrazine in alkaline solutions can be directly oxidised in glassy carbon porous electrodes to nitrogen, which facilitates its selective and sensitive determination in water

Table 3. Analysis of water samples for hydrazine

\begin{tabular}{|l|c|c|c|c|}
\hline \multicolumn{1}{|c|}{ Sample } & $\begin{array}{c}\text { Found, } \\
\mathrm{mg} \cdot \mathrm{dm}^{-3}\end{array}$ & $\begin{array}{c}\text { Reference value }{ }^{\mathrm{a}}, \\
\mathrm{mg} \cdot \mathrm{dm}^{-3}\end{array}$ & $\begin{array}{c}\text { Informative value }^{\mathrm{b}}, \\
\mathrm{mg} \cdot \mathrm{dm}^{-3}\end{array}$ & $\begin{array}{c}\text { Spike }^{\mathrm{c}} \text { recovery, }_{\%} \\
\%\end{array}$ \\
\hline Tap water I & $<0.008$ & $<0.01$ & - & 98.1 \\
\hline Tap water II & $<0.008$ & $<0.01$ & - & 97.2 \\
\hline River water & $<0.008$ & $<0.01$ & - & 102.5 \\
\hline Underground water & $<0.008$ & $<0.01$ & 0.076 & 95.0 \\
\hline Boiler water I & $0.071 \pm 0.009$ & $0.068 \pm 0.008$ & 0.048 & 103.1 \\
\hline Boiler water II ${ }^{\mathrm{d}}$ & $0.046 \pm 0.008$ & $0.044 \pm 0.008$ & 0.046 & 102.4 \\
\hline Boiler water III & $0.040 \pm 0.007$ & $0.035 \pm 0.007$ & - & \\
\hline
\end{tabular}

${ }^{\mathrm{a}}$ Spectrophotometry, ${ }^{\mathrm{b}}$ value obtained in the power plant laboratory, ${ }^{\mathrm{c}}$ samples spiked with $0.25 \mathrm{mg} \cdot \mathrm{dm}^{-3}$ hydrazine, ${ }^{\mathrm{d}}$ sample stabilized with hydrochloric acid

Confidence intervals calculated from 6 results at a confidence level of $95 \%$

Calibration curve for the range of $0-0.5 \mathrm{mg} \cdot \mathrm{dm}^{-3}$

Regression line: $\mathrm{y}=0.5974 \mathrm{x}-3.394$

Coefficient of determination $\mathrm{R}^{2}=0.9989$ 
samples. The elaborated procedure is simple and fast, and with the addition of a phosphate or borate electrolyte solution to the sample it can be directly analysed. For hydrazine contents above $0.7 \mathrm{mg} \cdot \mathrm{dm}^{-3}$ we used the E-53 microporous electrode, and for lower concentrations the macroporous E-104 electrode proved most suitable. The method can be used for various water samples, especially for boiler water with hydrazine contents down to $10 \mu \mathrm{g} \cdot \mathrm{dm}^{-3}$. The interfering effect of higher metal contents can be eliminated by the addition of EDTA. Ammonia interferes at concentrations above $10 \mathrm{mg} \cdot \mathrm{dm}^{-3}$ only. The main advantages of the employed porous electrodes is their long lifetime comprising several thousand measurements, with no requirement for manual regeneration or polishing, and a low price. The disadvantage of this method compared to some other published procedures is that it cannot address hydrazine concentrations below this detection limit. Nevertheless, owing to its simplicity and the availability of electrode materials the method can easily be used in routine laboratories. Moreover, it can also be adapted to electrochemical process and portable analyzers.

\section{Acknowledgements}

This publication was supported by the Competence Center for SMART Technologies for Electronics and Informatics Systems and Services, ITMS 26240220072, and by the Slovak Grant Agency VEGA (project No. $1 / 0419 / 12)$.

\section{References}

1. ASTM Manual of Industrial Water, D1385-78, 376, 1979.

2. SAFAVI A., ENSAFI A.A. Kinetic spectrophotometric determination of hydrazine. Anal. Chim. Acta 300, 307, 1995.

3. SZEBELLEDY L., SOMOGYI Z. Coulometric analysis as methods of precision. V. Determination of hydrazine. Z . Anal. Chem. 112, 391, 1938

4. IKEDE S., SUTAKE H., KOHRI Y. Flow injection analysis with an amperometric detector utilizing the redox reaction of iodate ion. Chem. Lett. 6, 873, 1984.

5. MCBRIDE W.R., HENRY R.A., SKOLNIK S. Potentiometric analytical methods for hydrazino compounds. Anal. Chem. 23, 890, 1951.

6. GAWARGIOUS Y.A., BESEDA A. Iodometric microdetermination of hydrazine by amplification reactions. Talanta 22, 757, 1975 .

7. SAFAVI A., BAEZZAT M.R. Flow injection chemiluminescence determination of hydrazine. Anal. Chim. Acta 358, $121,1998$.

8. KORINEK K., KORYTA J., MUSILOVA M. Electrooxidation of hydrazine on mercury, silver, and gold electrodes in alkaline solutions. J. Electroanal. Chem. 21, 319, 1969

9. EISNER U., ZEMER Y. Anodic oxidation of hydrazine and its derivatives. III. Oxidation of methyl hydrazine on mercury electrodes in alkaline solution. J. Electroanal. Chem. 34, 81, 1972.
10. FLEISCHMANN M., KORINEK K., PLETCHER D. Oxidation of hydrazine at a nickel anode in alkaline solution. J. Electroanal. Chem. 34, 499, 1972.

11. TANG Y.-Y., KAO C.-L., CHEN P.-Y. Electrochemical detection of hydrazine using a highly sensitive nanoporous gold electrode. Anal. Chim. Acta, 711, 32, 2012.

12. PETEK M., BRUCKENSTEIN S. Isotopic labelling investigation of the mechanism of the electro oxidation of hydrazine at platinum. Electrochemical mass spectrometric study. J. Electroanal. Chem., 47, 329, 1973.

13. ROSCA V., KOPER M. T. M. Electrocatalytic oxidation of hydrazine on platinum electrodes in alkaline solutions. Electrochim. Acta 53, 5199, 2008

14. ROSCA V., DUCA M., DE GROOT M. T., KOPER M. T. M. Nitrogen Cycle Electrocatalysis. Chem. Rev. 109, 2209, 2009.

15. ALDOUS L., COMPTON R. G. The mechanism of hydrazine electro-oxidation revealed by platinum microelectrodes: role of residual oxides. Phys. Chem. Chem. Phys. 13, 5279,2011

16. SUN H., DONG L., YU H., HUO M. Direct electrochemical oxidation and detection of hydrazine on a boron doped diamond (BDD) electrode. Russian J. Electrochem. 49, 883, 2013.

17. JAYASRI D., NARAYANAN S.S. Amperometric determination of hydrazine at manganese hexacyanoferrate modified graphite-wax composite electrode. J. Hazard. Mater. 144, 348, 2007.

18. AZIZ M.A., KAWDE A.-N. Gold nanoparticle-modified graphite pencil electrode for the high-sensitivity detection of hydrazine. Copper-palladium alloy nanoparticle plated electrodes for the electrocatalytic determination of hydrazine. Talanta 115, 214, 2013.

19. YANG C.-C., KUMAR A.S., KUO M.-C., CHIEN S.-H., ZEN J.-M. Copper-palladium alloy nanoparticle plated electrodes for the electrocatalytic determination of hydrazine. Anal. Chim. Acta, 554, 66, 2005.

20. MAZLOUM-ARDAKANI M., KHOSHROO A. An electrochemical study of benzofuran derivative in modified electrode-based CNT/ionic liquids for determining nanomolar concentrations of hydrazine. Electrochim. Acta 103, 77, 2013.

21. DIAS F. X., JASELSKIS B. Voltammetric determination of hydrazine and hydroxylamine. Analyst 108, 76, 1983.

22. RAOOF J.-B., OJANI R., RAMINE M. Electrocatalytic oxidation and voltammetric determination of hydrazine on the tetrabromo-p-benzoquinone modified carbon paste electrode. Electroanalysis 19, 597, 2007.

23. ENSAFI A. A., LOTFI M., KARIMI-MALEH H. New Modified-Multiwall Carbon Nanotubes Paste Electrode for Electrocatalytic Oxidation and Determination of Hydrazine Using Square Wave Voltammetry. Chinese J. Catalysis 33, 487, 2012.

24. RAOOF J.-B., OJANI R., MOHAMMADPOUR Z. Electrocatalytic Oxidation and Voltammetric Determination of Hydrazine by 1,1'-Ferrocenedicarboxylic Acid at Glassy Carbon Electrode. Int. J. Electrochem. Sci. 5, 177, 2010.

25. MAZLOUM-ARDAKANI M., SADEGHIANE A., MOOSAVIZADEH S. H., KARIMI M. A., MASHHADIZADEH M. H. Electrocatalytic Determination of Hydrazine using Glassy Carbon Electrode with Calmagates. Anal. Bioanal. Electrochem. 4, 224, 2009.

26. RAOOF J.-B., OJANI R., JAMALI F., HOSSEINI S. R. Electrochemical detection of hydrazine using a copper oxide nanoparticle modified glassy carbon electrode. Caspian J. Chem. 1, 73, 2012. 
27. CHAKRABORTY S., RAJ C. R. Carbon nanotube supported platinum nanoparticles for the voltammetric sensing of hydrazine. Sensors and Actuators B: Chemical 147, 222, 2010.

28. PINTER J. S., BROWN K. L., DEYOUNG P. A., PEASLEE G. F. Amperometric detection of hydrazine by cyclic voltammetry and flow injection analysis using ruthenium modified glassy carbon electrodes. Talanta 71, 1219, 2007.

29. CONCEIÇÃOA C. D. C., FARIAA R. C., FATIBELLOFILHOA O., TANAKAB A. A. Electrocatalytic Oxidation and Voltammetric Determination of Hydrazine in Industrial Boiler Feed Water Using a Cobalt Phthalocyanine-modified Electrode. Anal. Lett. 41, 1010, 2008.

30. SHANG L., ZHAO F., ZENG B. Electrocatalytic Oxidation and Determination of Hydrazine at an $\mathrm{AuCu}$ Nanoparticles - Graphene - Ionic Liquid Composite Film Coated Glassy Carbon Electrode. Electroanalysis 24, 2380, 2012.

31. BARON R., ŠLJUKIĆ B., SALTER C., CROSSLEY A., COMPTON R. G. Development of an electrochemical sensor nanoarray for hydrazine detection using a combinatorial approach. Electroanalysis 19, 1062, 2007.

32. BEINROHR E. Flow-Through Chronopotentiometry in Waste Water Analysis, In: F.S.G. Einschlag (Ed): Waste Water. Evaluation and Management, InTech, Rijeka, Croatia, pp. 71-92, 2011.

33. BEINROHR E., CAKRT M., DZUROV J., JURICA L., BROEKAERT J.A.C. Simultaneous calibrationeless deter- mination of zinc, cadmium, lead and copper by flowthrough stripping chronopotentiometry. Electroanalysis 11, 1137, 1999.

34. THOMSEN K.N., SKOV H.J., DAM M.E.R. A flexible instrument for voltammetry, amperometry and stripping potentiometry. Anal. Chim. Acta 293, 1, 1994.

35. HU A., DESSY R.E., GRANELI A. Potentiometric stripping with matrix exchange techniques in flow injection analysis of heavy metals in groundwaters. Anal. Chem. 55, 320, 1983.

36. BARD A.L., FAULKNER L.R. Electrochemical Methods, Chapter 10.6, Wiley, New York, 1980.

37. BEINROHR E. Flow-through coulometry as a calibrationless method in inorganic trace analysis. Accred. Qual. Assur. 6, 321, 2001

38. HALL H. K. Correlation of the Base Strengths of Amines. J. Am. Chem. Soc. 79, 5441, 1957.

39. SAND H. J. S. On the concentration at the electrodes in a solution, with special reference to the liberation of hydrogen by electrolysis of a mixture of copper sulphate and sulphuric cid. Philosophical Magazine 1, 45, 1901.

40. MOCAK J., BOND A. M., MITCHELL S., SCOLLARY G. A statistical overview of standard (IUPAC and ACS) and new procedures for determining the limits of detection and quantification: Application to voltammetric and stripping techniques (technical report). Pure Appl. Chem. 69, 297, 1997. 